\title{
RELATO DE EXPERIÊNCIA SOBRE VIOLÊNCIA OBSTÉTRICA EM UMA RODA DE CONVERSA
}

\section{EXPERIENCE REPORT ON OBSTETRIC VIOLENCE IN A CONVERSATION WHEEL}

\author{
Aline Passos Santos \\ Carla de Quadros ${ }^{\star *}$
}

\begin{abstract}
RESUMO: A Lei 11.340/2006, conhecida como Lei Maria da Penha, cria mecanismos para coibir e prevenir a violência doméstica e familiar contra a mulher, com respaldo de organismos internacionais, tendo em vista o descaso que a violência doméstica sempre foi tratada no Brasil. Desse modo, o presente estudo tem como objetivo apresentar a experiência de uma roda de conversa sobre violência obstétrica, realizada na Semana Acadêmica da Faculdade de Ciências e Empreendedorismo, em novembro de 2019, no Município de Santo Antônio de Jesus-BA. Foram abordadas algumas questões pontuais sobre a violência contra a mulher, numa tentativa de aliar a teoria com a prática, de modo a repensar a aplicabilidade da Lei Maria da Penha para os casos de violência obstétrica. Trata-se de uma metodologia observacional a partir de uma roda de conversa. Como resultados, percebeu-se que as rodas de conversas possibilitam achados científicos, além de contribuir para o empoderamento feminino e partilhamento de experiências e (re)significação de comportamentos. A falta de informação, aliada ao medo, vergonha de denunciar ou até mesmo a romantização do parto são elementos que cooperam para o silenciamento de muitas mulheres vítimas da violência obstétrica. Por fim, entende-se pela possibilidade de aplicação da Lei Maria da Penha aos casos de violência obstétrica.
\end{abstract}

PALAVRAS-CHAVE: Direitos sexuais e reprodutivos. Parto humanizado. Planejamento familiar. Violência doméstica.

ABSTRACT: Law 11.340/2006, known as the Maria da Penha Law, creates mechanisms to curb and prevent domestic and family violence against women, with the support of international organizations in view of the neglect that domestic violence has always been addressed in Brazil. Thus, the present study aims to present the experience of a conversation round about obstetric violence that took place at the Academic Week of the Faculty of Science and Entrepreneurship, held in November

\footnotetext{
* Servidora técnica da Universidade Federal do Recôncavo e Professora da área de Direito da FAMAM. ** Possui graduação em Letras vernáculas pela Universidade do Estado da Bahia (2000), graduação em Direito - Valença pela Universidade do Estado da Bahia (2016), Especialização em Estudos Comparados em Literatura de Língua Portuguesa pela Universidade Estadual de Santa Cruz (2002), Especialização em Antropologia (2018), mestrado em Literatura e Diversidade Cultural pela Universidade Estadual de Feira de Santana (2008) e doutorado em Letra ,Linguística e Literatura pela Pontifícia Universidade Católica do Rio Grande do Sul (2010). Atualmente é professora adjunta e coordenadora de área na Universidade do Estado da Bahia. Professora - na Secretaria de Educação do Estado da Bahia.
} 
2019, in the Municipality of Santo Antônio de Jesus-BA. on violence against women, in an attempt to combine theory with practice, in order to rethink the applicability of the Maria da Penha Law to cases of obstetric violence. It is an observational methodology based on a conversation wheel. As results it was realized that the conversation wheels enable scientific findings, besides contributing to female empowerment and sharing of experiences. The lack of information, coupled with fear, shame of denouncing or even romanticizing childbirth, makes many women victims of obstetric violence silenced. Finally, it is understood the possibility of applying the Maria da Penha Law to cases of obstetric violence.

KEYWORDS: Sexual and reproductive rights. Humanized birth; family planning. Domestic violence

\section{INTRODUÇÃO}

A violência obstétrica é perpetrada contra mulheres em um período de vulnerabilidade, ou seja, perpassa o percurso do período gestacional, do parto, pósparto e inclusive no atendimento ao abortamento. Ela se traduz de diversas formas, sendo resultado da violência psicológica, física, verbal, simbólica, ou sexual, além da negligência, discriminação ou condutas excessivas desnecessárias, muitas vezes prejudiciais e sem embasamento em evidências científicas.

Trata-se de uma das modalidades de violência de gênero, já que há uma tentativa de apropriação e violação do corpo feminino e do seu processo de reprodução. São várias as táticas do patriarcado para o controle dos corpos femininos - desde o tabu da virgindade até à criminalização do aborto. Expressões como "ser mãe é padecer no paraíso" ou "as mulheres são mais tolerantes à dor que o homem" são discursos construídos e repetidos a fim de justificar o sofrimento evitável como fonte da natureza dos corpos. Não há destino biológico que justifique a violência obstétrica: ela é intencionalmente provocada nas mulheres ou negligentemente desencadeada e naturalizada.

Desse modo, o presente estudo tem como objetivo apresentar a experiência de uma roda de conversa sobre violência obstétrica que ocorreu na Semana Acadêmica da Faculdade de Ciências e Empreendedorismo, realizada em novembro de 2019, no Município de Santo Antônio de Jesus-BA. O objetivo da atividade foi apresentar pontos essenciais de violência contra a mulher, informar aos participantes sobre a ocorrência da violência obstétrica, bem como trazer relatos de mulheres que passaram por essa 
experiência traumática no momento de intimidade e vulnerabilidade. Na mediação desses relatos, buscou-se aliar a teoria com a prática, propiciando-se um repensar acerca da aplicabilidade da Lei Maria da Penha, e dos direitos sexuais e produtivos da mulher. Tratou-se de uma experiência de discentes do curso de direito, docentes, e comunidade externa.

A conscientização de mulheres sobre a violência obstétrica internacionalmente, a manutenção dos índices de violência e mortalidade no Brasil, e a luta pela implementação pelos direitos femininos têm sido fortemente impulsionados pela ação de mulheres organizadas na sociedade civil, bem como nos conselhos de classe, como é o caso da OAB. (ARAUJO, 2017). Desse modo, tal pesquisa justifica-se em razão da necessidade de ampliar o debate sobre o tema, possibilitando a divulgação das informações para toda a sociedade. Ressalte-se que em Santo Antônio de Jesus já existe um movimento acadêmico e popular com discussões da temática em cursos, seminários, oficinas, mesas, minicursos, palestras e outras atividades. Em outras instâncias acadêmicas, outras instituições de ensino da região, como a Universidade Federal do Recôncavo da Bahia - UFRB e a Universidade do Estado da Bahia - UNEB têm promovido debates sobre violência contra a mulher, abrangendo também a violência obstétrica.

As rodas de conversas com temáticas voltadas à mulher são fundamentais para desenvolver a emancipação, a percepção do respeito mútuo e apoio, o desenvolvimento do engajamento, corresponsabilização e participação social, além de estimular mulheres a compreenderem sua inserção histórica para que se sintam capazes e motivadas a intervir em sua realidade e de outras mulheres, implicando, portanto, em consideráveis avanços na busca pela igualdade de direitos e consolidação da democracia. Por outro lado, os relatos de experiência potencializam o tema escolhido na medida em que diversifica o olhar, estimulando a participação e a criação de práticas educativas.

\section{METODOLOGIA}


A Roda de conversa intitulada "Violência Obstétrica: o direito ao parto humanizado" fez parte de um evento estudantil, que se iniciou com uma caminhada envolvendo a comunidade local, realização de palestras, oficinas, e diversas atividades que tratam da temática de gênero, com o objetivo de empoderar e transformar as estruturas sociais visando à redistribuição de poder.

A oficina contou com 50 participantes, com faixa etária de 20 a 35 anos. As inscrições foram realizadas a partir do interesse dos participantes mediante plataforma online, com participação majoritária de mulheres. As atividades foram conduzidas com sala organizada em círculo, a fim de facilitar a interação entre as/os participantes. Convidadas a falar sobre a violência obstétrica e suas vivências sobre a temática, através de uma dinâmica com caixa que circulava com situações, frases ou imagens relacionadas a temática. Em seguida, tratou sobre o tema com a exposição de algumas imagens, com vistas a provocar uma reflexão inicial sobre as condutas de violência obstétrica. A abordagem do tema deu-se, primeiramente, definindo-se o título da oficina, além de assinalar a relação do termo com a luta por direitos civis, direitos sexuais e reprodutivos das mulheres e a relevância desse ato para a democracia.

A Roda de Conversa é, dentro da pesquisa narrativa, uma forma de coleta de dados em que o pesquisador se insere como sujeito da pesquisa pela participação na conversa e, ao mesmo tempo, produz dados para discussão. É, na verdade, um instrumento que permite a partilha de experiências e o desenvolvimento de reflexões sobre as práticas educativas dos sujeitos, em um processo mediado pela interação com os pares, mediante diálogos internos, e, ainda, no silêncio observador e reflexivo (MOURA; LIMA, 2015).

A proposta da roda de conversa partiu do corpo discente e teve o apoio de professoras mestras e doutoras, além de contar com a participação da convidada externa da área de saúde. Tal atividade foi elencada no eixo temático relacionado aos direitos humanos, direitos reprodutivos, inclusão e responsabilidade social. Esse tipo de atividade permite encontros dialógicos, criando possibilidades de produção e ressignificação de sentido - saberes - sobre as experiências dos partícipes. Sua escolha se baseia na horizontalização das relações de poder. Os sujeitos que as 
compõem se implicam, dialeticamente, como atores históricos e sociais críticos e reflexivos diante da realidade. Dissolve-se a figura do mestre, como centro do processo, e emerge a fala como signo de valores, normas, cultura, práticas e discurso. (SAMPAIO et al., 2014).

A abordagem partiu de um contexto interdisciplinar, perpassando pelo Direito Constitucional na perspectiva dos direitos fundamentais, especialmente do princípio da dignidade da pessoa humana. No campo do direito civil, pelo viés da responsabilidade civil, além do direito penal, e da legislação extravagante, com a abordagem sobre a Lei Maria da Penha, o Código de Ética Médica e direitos sexuais reprodutivos. Após a roda de conversa, os discentes realizaram relatórios de suas vivências, com as suas percepções particulares, de modo a contribuir com os resultados e discussões deste trabalho, além das considerações finais.

\section{VIOLÊNCIA OBSTÉTRICA}

A palavra violência surgiu do latim - violentia-, que significa caráter violento ou bravio. A expressão violare quer dizer lidar com violência, ofender, transgredir. Esses termos devem ser mencionados com desprezo, a força em ação, o recurso de um corpo para realizar a sua força e, com isso, a eficiência, o valor, ou seja, a força vital (CAVALCANTE, 2007).

A violência contra a mulher é denominada como um fenômeno histórico, pois a mulher era (re)conhecida como um indivíduo sem expressão e sem vontade próprias no âmbito familiar e não tinha o direito de expor sua opinião, sendo obrigada a aceitar ordens que, primeiro vinham de seu genitor e, após o casamento, de seu cônjuge, condição organizada e retroalimentada pelo patriarcado. (MELLO, 2007).

O direito romano é um exemplo de como o homem exercia posição de destaque perante a mulher. De acordo com a Lei das Doze Tábuas, o pater famílias, era o estatuto familiar mais alto, considerava que o ascendente mais velho era quem detinha soberania frente aos descendentes, e também possuía o vitae necisque potestas, ou seja, o poder da vida e da morte sobre seus filhos, sua esposa (em alguns 
casos) e seus escravos. Logo, percebe-se que o domínio dos nossos corpos sempre foi exercício ativo e estimulado, tornando-se estrutural. (ROMANO, 2017).

Ao terem de exercer a maternidade de forma compulsória, as mulheres perderam a autodeterminação sobre seus próprios corpos, passando a ser reguladas pelo Estado, pela sociedade e pela igreja, sob uma lógica patriarcal e machista que define o lugar social da mulher/mãe consagrada inclusive ao sofrimento na hora do parto. Essas determinações se devem, em grande parte, às características físicas entres os corpos femininos e masculinos, que foram historicamente interpretadas, pelos homens, e reproduzidas em equipamentos culturais que retroalimentam, como sendo definidoras dos papéis sociais que exercem (MATTAR; DINIZ, 2012).

A violência obstétrica se constitui, portanto, como uma violência de gênero, pois, como aponta Saffioti (2004), as mulheres são "amputadas", sobretudo no desenvolvimento, uso da razão e no exercício do seu poder". A socialização das mulheres sofreu influência do conformismo e da docilidade, enquanto os homens receberam estímulo social voltado para a coragem e a força, logo esses corpos femininos não podem exercer vários direitos, inclusive os sexuais, sendo a maternidade o destino das mulheres que devem padecer no paraíso. (SAFFIOTI, 2004).

De fato, ao longo da história, a mulher sofreu com a subordinação e discriminação relacionada à questão de gênero, de modo que seu papel era limitado perante o corpo social. Assim sendo, desde a Idade Antiga a figura feminina era vista como inferior, sobretudo sendo condicionada, muitas vezes, a exercer apenas as funções de mãe e/ou esposa e as tarefas domésticas. Ou seja, ela nunca era percebida pelo que, de fato, representava, bem como a sua importância para a coletividade e para o eixo familiar. À mulher cabia apenas o reconhecimento e o espaço doméstico (MAGALHÃES, 1980).

A evolução da medicina, a descoberta de métodos contraceptivos, bem como as lutas emancipatórias promovidas pelos movimentos feministas levaram à redefinição do modelo ideal de família. A mulher (branca, pois as negras trabalhavam e muito) ao ingressar no mercado de trabalho, passou a ser, também, provedora do lar, mas isso não redefiniu os papeis, pelo contrário, responsabilidades domésticas e 
cuidado com a prole continuavam a cargo das mulheres quando chegavam da jornada, tendo assim uma dupla jornada, ou entregues a empregadas domésticas, continuando as desigualdades sociais. (DIAS, 2019).

Nesse viés, a violência contra a mulher é um fenômeno complexo que pode estar presente em todas as esferas e momentos da vida, podendo ser apresentada de diferentes formas e circunstâncias diversas. Em virtude disso, a violência pode ocorrer através da violência física, psicológica, sexual, simbólica, sendo que não se expressa apenas no corpo, muitas vezes não deixa sinais perceptíveis, repercutindo na vida social da mulher (DINIZ et al., 2003).

Todas as mulheres, independente da classe e da raça/etnia em uma sociedade patriarcal, estão sujeitas a sofrer violência, mas não indiferenciadamente. Ou melhor, a classe e a raça/etnia não apenas imprimem novas determinações de violência, mas também tornam algumas mulheres mais propensas a violências, além de serem as mulheres negras, pobres e periféricas as que mais têm dificuldades materiais para o enfrentamento dessas violências, posto que além de patriarcal, essa sociedade organiza-se de forma racista e classista (CIRNE, 2015).

Dados apresentados pelo Atlas da Violência do Instituto de Pesquisa Econômica Aplicada (2019) demonstram que houve um crescimento dos homicídios femininos no Brasil em 2017, com cerca de 13 assassinatos por dia. Ao todo, 4.936 mulheres foram mortas, o maior número registrado desde 2007. Dados que têm chamado a atenção da mídia, dos operadores do direito e dos pesquisadores sobre segurança pública no país (IPEA,2019).

A magnitude do fenômeno e de suas variações pode ser melhor aferida em termos da taxa de homicídio por grupo de 100 mil mulheres, que permite maior comparabilidade temporal e entre as diferentes unidades federativas. Entre 2007 e 2017 houve aumento de 20,7\% na taxa nacional de homicídios de mulheres, quando a mesma passou de 3,9 para 4,7 mulheres assassinadas por grupo de 100 mil mulheres. Nesse período, houve crescimento da taxa em 17 Unidades da Federação. Já no recorte de 2012 a 2017, observamos aumento de 1,7\% na taxa nacional e um aumento maior ainda de $5,4 \%$ no último ano, período em que se verificam taxas ascendentes em 17 UFs em relação a 2016 (IPEA, 2019). 
A definição objetiva dos tipos de violência é importante para destacar as diferentes formas de expressão da violência e que, por muito tempo, não foram vistas como tais ou não receberam o devido cuidado e atenção. Nesse sentido, abriu-se espaço para o destaque da violência obstétrica como um tipo específico de violência contra a mulher que merece reconhecimento, pois, ainda que o tema estivesse na pauta feminista e até mesmo contemplada em políticas públicas, foi relativamente negligenciado, diante da resistência dos profissionais e de outras questões urgentes na agenda dos movimentos, assim como a falta de acesso das mulheres pobres a informações e serviços essenciais (DINIZ et al, 2015).

Ao tratar sobre os tipos de violências perpetradas contra as mulheres, Mirla Cirne (2015) destaca a violência obstétrica enquanto uma violência diferente das demais, não necessariamente é praticada pelo cônjuge ou ex-cônjuge, embora também seja comum eles a praticarem, ao, por exemplo, obrigarem uma mulher a abortar, ao xingarem mulher quando ela não consegue amamentar ou até mesmo por resumirem a mulher à gestação e/ou à maternidade. Vinculada a uma perspectiva conservadora de maternidade, a violência obstétrica pode se manifestar na gestação, parto (inclusive, a proibição do direito a um(a) acompanhante no momento do parto), pós-parto, amamentação, exames de toque, esterilizações não consentidas, em situações de abortamento etc. Nessa forma de violência, pesa um forte moralismo sobre a mulher e uma cobrança social de um modelo de maternidade abnegada, na qual a mulher deve estar pronta para qualquer sacrifício, ainda que isso signifique passar por cima de suas necessidades.

Segundo dados da Fundação Perseu Abramo (2010), uma em cada quatro mulheres brasileiras relata ter sofrido algum tipo de violência durante o evento de trabalho de parto, ou ainda sobre o estado puerperal, sendo agravada a situação quando se trata de mulheres atendidas em redes públicas de saúde.

Percebe-se, portanto, a partir dos atendimentos de violências sofridas realizado pelo SUS, que as mulheres são muito mais vulneráveis às violências - em razão da cultura misógina em que se vive - e representam a grande maioria dos atendimentos relativos a violências, especialmente às domésticas cometidas na própria residência e por parentes imediatos, companheiros ou ex-companheiros, dados esses que 
apenas corroboram com o que está sendo afirmado até o momento: vive-se uma cultura da violência, especialmente contra a mulher (AMORIM, 2019).

A Federação Brasileira das Associações de Ginecologia e Obstetrícia (FEBRASGO) define a violência obstétrica como "uso intencional de força física ou poder, em ameaça ou na prática, contra si próprio, outra pessoa ou contra um grupo ou comunidade que resulte ou possa resultar em sofrimento, morte, dano psicológico, desenvolvimento prejudicado ou privação", em qualquer momento da gestação, parto ou puerpério (FEBRASGO, 2019). A Organização Mundial da Saúde (2014) em publicação da "Declaração para prevenção e eliminação de abusos, desrespeito e maus-tratos durante o parto em instituições de saúde" define e denuncia o seguinte: "Toda mulher tem direito ao melhor padrão atingível de saúde, o qual inclui o direito a um cuidado de saúde digno e respeitoso... No mundo inteiro, muitas mulheres sofrem abusos, desrespeito e maus-tratos durante o parto nas instituições de saúde. Tal tratamento não apenas viola os direitos das mulheres ao cuidado respeitoso, mas também ameaça o direito à vida, à saúde, à integridade física e à não-discriminação..." (OMS, 2014).

No mesmo sentido, vale ressaltar que a violação aos direitos reprodutivos é considerada uma das formas de violência contra a mulher por incidir sobre os caracteres ontológicos que mais claramente diferenciam homens e mulheres, na acepção fisiológica do termo. A violação e a falta de atenção às peculiaridades inerentes à condição e à fisiologia feminina são características de uma sociedade que relega a figura da mulher a um papel secundário, reafirmando as relações de poder e dominação da medicina e do machismo na estruturação de práticas assistenciais (SERAFIM, 2017).

É importante ressaltar que, no Brasil, ao contrário de países como Argentina (Lei Nacional no 25.929) e Venezuela (Guerra, 2012), ainda não consta na legislação uma lei específica que caracterize a violência obstétrica. Conforme definição da Defensoria Pública do Estado de São Paulo (DPESP, 2013), violência obstétrica caracteriza-se pela apropriação do corpo e dos processos reprodutivos das mulheres pelos profissionais de saúde, através do tratamento desumanizado, abuso da medicalização e patologização dos processos naturais, causando a perda da 
autonomia e capacidade de decidir livremente sobre seus corpos e sexualidade, impactando negativamente na qualidade de vida das mulheres (DPESP, 2013).

Diante da condição de violência obstétrica que muitas mulheres sofrem no atendimento de saúde, quer seja durante a gestação, parto ou pós-parto imediato, o Núcleo Especializado de Promoção e Defesa dos Direitos da Mulher da Defensoria Pública do Estado de São Paulo publicou, em 2015, material informativo, intitulado "Conversando sobre violência obstétrica". Essa publicação apresenta dado de conformismo ao sofrimento por parte de muitas mulheres, apontando: "Algumas mulheres acreditam que o parto é um processo sofrido e, por essa razão, não se surpreendem quando vivenciam uma experiência ruim" (DEFENSORIA PÚBLICA/SP, 2015).

O dado mencionado pela Defensoria Pública (DP) do estado de São Paulo (2015) demonstra que muitas mulheres não se dão conta de estarem sendo vítimas desse tipo de violência, por ser uma situação mascarada como cotidiana e normal. Desse modo, percebe-se o quanto o processo de empoderamento é crucial para a mudança da realidade das mulheres, para que elas possam viver com liberdade e igualdade.

\section{DIREITOS SEXUAIS E REPRODUTIVOS DAS MULHERES}

A Constituição da República Federativa do Brasil em seu artigo 226, especifica que a família, base da sociedade, tem especial proteção do Estado. A Lei Maria da Penha, portanto, veio fortalecer ainda mais esse mandamento constitucional. Numa perspectiva internacional diversos acordos internacionais garantem a Proteção à Mulher: I Conferência Mundial sobre a Mulher (México), a Convenção sobre a Eliminação de Todas as Formas de Discriminação contra as mulheres, A Conferência de Direitos Humanos das Nações Unidas (Viena, Austria), Convenção de Belém do Pará, entre tantos outros.

Segundo a Conferência de Pequim, em 1995, em seu parágrafo 94, define-se direitos reprodutivos são definidos como algo que transcende a ausência de doença ou enfermidade, relacionando-se a um bem-estar físico, mental e social em todas as 
matérias relacionadas com o sistema reprodutivo, suas funções e seus processos. Para tanto, deve ser garantida às mulheres a capacidade de reproduzir-se, bem como a liberdade de decidir se e como fazê-lo, incluindo o acesso a métodos e informações de planejamento familiar e assistência de serviços de saúde adequados (SERAFIM, 2017).

A concepção dos direitos reprodutivos exclusivamente como liberdade reprodutiva, baseada em escolhas individuais que se dão em um âmbito privado, foi amplamente criticada pelas feministas no processo de construção e consolidação destes direitos. Isto porque consideram que as escolhas reprodutivas se dão em condições de desigualdades de gênero, classe, cultura, além de ignorar que é justamente no âmbito privado onde ocorrem as maiores violações ao direito das mulheres decidirem sobre os usos de seu corpo. Estes debates evidenciaram que, diante de grupos sociais privados de direitos, não é possível falar em liberdades privadas ou escolhas individuais desvinculadas dos contextos em que se realizam (MATTAR LD, 2012).

No Brasil, o reconhecimento destes direitos encontra-se claramente expresso na Constituição Federal Brasileira que, em seu art. 226, $§ 7$, dispõe que sobre o direito ao planejamento familiar, e na Lei Federal no 9.263 de 1996, que garantiu direitos iguais de constituição, limitação ou aumento da prole à mulher, ao homem ou ao casal. Esta lei, numa visão de atendimento global e integral à saúde, atribuiu às instâncias gestoras do SUS, em todos os seus níveis, a responsabilidade pela assistência ao planejamento familiar e pelas ações preventivas e educativas, reconhecendo o dever do estado em promover condições e recursos informativos, educacionais e científicos que assegurem o livre exercício desse direito (DIUANA, 2016).

A inclusão dos direitos sexuais e reprodutivos no campo do direito à saúde e à valorização da mulher como sujeito de direito pleno em convenções internacionais de direitos humanos, em Declarações e Planos de Ação de Conferências das Nações Unidas, e em legislações nacionais, como a Constituição Federal de 1988, trouxeram novos desafios para o debate sobre o direito de escolha no que se refere à vida reprodutiva. Apontou também a questão da responsabilidade do Estado frente a tais escolhas (PITANGUY,2016). 
O efetivo exercício dos direitos reprodutivos demanda políticas públicas que assegurem a saúde sexual e reprodutiva. Nesta ótica, fundamental é o direito ao acesso a informações, meios e recursos seguros, disponíveis e acessíveis. Fundamental também é o direito ao mais elevado padrão de saúde reprodutiva e sexual, tendo em vista a saúde não como mera ausência de enfermidades e doenças, mas como a capacidade de desfrutar de uma vida sexual segura e satisfatória e reproduzir-se com a liberdade de fazê-lo ou não, quando e com que frequência. Incluise ainda o direito ao acesso ao progresso científico e o direito de receber educação sexual. Portanto, aqui é essencial a interferência do Estado, no sentido de implementação de políticas públicas que assegurem o direito à saúde sexual e reprodutiva (PIOVESAN, 2002).

\section{APLICABILIDADE DA LEI MARIA DA PENHA AOS CASOS DE VIOLÊNCIA OBSTÉTRICA}

A elaboração de uma lei específica para a violência de gênero foi resultado do trabalho e da mobilização dos movimentos de mulheres, potencializado pela criação da Secretaria Especial de Políticas para as Mulheres da Presidência da República. A Lei 11.340/20062, denominada de Lei Maria da Penha, fundamenta-se em normas e diretivas consagradas na Constituição Federal, na Convenção da ONU sobre a Eliminação de Todas as Formas de Violência contra a Mulher e na Convenção Interamericana para Punir e Erradicar a Violência contra a Mulher.

Para a Convenção sobre a Eliminação de todas as formas de Discriminação contra a Mulher, a discriminação contra a mulher significa "toda distinção, exclusão ou restrição baseada no sexo e que tenha por objeto ou resultado prejudicar ou anular o reconhecimento, gozo, exercício pela mulher, independentemente de seu estado civil, com base na igualdade do homem e da mulher, dos direitos humanos e das liberdades fundamentais nos campos político, econômico, social, cultural e civil ou em qualquer outro campo." (art. $1^{\circ}$ ). Isto é, a discriminação significa toda distinção, exclusão, restrição ou preferência que tenha por objeto ou resultado prejudicar ou anular o 
reconhecimento, gozo ou exercício pela mulher, em igualdade de condições, dos direitos humanos e liberdades fundamentais.

A Lei Maria da Penha trata de vários tipos de violência que são perpetrados contra as mulheres: violência moral, psicológica, patrimonial, sexual e a violência física, embora esse rol não seja exaustivo, uma vez que a própria Lei em seu artigo $7^{\circ}$ faz referência a "entre outras", entendendo-se, portanto, que existem outras formas de violência.

Maria Berenice Dias (2019) assim dispõe: a tipificação penal é bastante restrita e exige inúmeros outros requisitos além da simples violência. Por isso, não se justifica restringir o reconhecimento da violência no âmbito das relações domésticas à configuração do tipo penal correspondente. A Lei Maria da Penha vem indicar ações e espaços onde é possível configurar a violência contra a mulher, especificando o âmbito da unidade doméstica, da família e em qualquer relação de afeto. Sendo assim, entende-se por perfeitamente aplicável aos casos de violência obstétrica a aplicação da Lei Maria da Penha, uma vez que, da relação paciente e médico, existe uma relação profissional, muitas das vezes marcada por uma relação de afeto de quem foi acompanhada durante todo o período gestacional.

As medidas previstas na Lei Maria da Penha podem ser organizadas em três eixos de intervenção. O primeiro eixo trata das medidas criminais, para a punição da violência. Nele estão procedimentos como a retomada do inquérito policial, a prisão em flagrante, preventiva ou decorrente de pena condenatória; a restrição da representação criminal para determinados crimes e o veto para a aplicação da lei 9099/95 a qualquer crime que se configure como violência doméstica e familiar contra a mulher. No segundo eixo, encontram-se as medidas de proteção da integridade física e dos direitos da mulher executáveis através de um conjunto de medidas protetivas com caráter de urgência para a mulher aliado a um conjunto de medidas que se voltam ao seu agressor. Integram também esse eixo as medidas de assistência, o que faz com que a atenção à mulher em situação de violência se dê de forma integral, contemplando o atendimento psicológico, jurídico e social. Finalmente, no terceiro eixo, estão as medidas de prevenção e de educação, compreendidas como 
estratégias possíveis e necessárias para coibir a reprodução social da violência e da discriminação baseadas no gênero (PASINATO, 2008, 2009).

Guilherme de Souza Nucci (2017) afirma que a Lei, ao proteger as relações de intimidade, extrapola o espírito dos tratados ratificados pelo Brasil, uma vez que a Convenção Interamericana para Prevenir, Punir e Erradicar a Violência contra a Mulher prevê como doméstica.

O estresse crônico gerado em razão da violência também pode desencadear sintomas físicos, como dores de cabeça, fadiga, dores nas costas e até distúrbios do sono. É o que se chama de transtorno de estresse pós-traumático. É identificado pela ansiedade e depressão, a ponto de baixar ou reduzir a capacidade da vítima em suportar os efeitos de um trauma severo. Como estes sintomas podem perdurar no tempo, independente da natureza da lesão corporal praticada, ocorrendo incapacidade para as ocupações habituais por mais de 30 dias ou incapacidade permanente para o trabalho, é possível tipificar o delito como lesão grave ou gravíssima, pela perpetuação da ofensa à saúde (DIAS, 2019).

Diante desta nova realidade, não há como restringir o alcance da previsão legal. Não importa o período do relacionamento e nem o tempo decorrente desde o seu rompimento. Basta a comprovação de que a ação agressiva decorreu da relação de afeto. Até vínculos afetivos que retornem ao conceito de família e de entidade familiar não deixam de ser marcados pela violência. Mesmo que não vivam sob o mesmo teto, havendo violência, merece a mulher receber o abrigo da Lei Maria da Penha. Para a configuração da violência como doméstica é necessário um nexo entre a agressão e a situação que a gerou, ou seja, a relação de afeto deve ser a causa da violência. (MISAKA, 2007). Expressamente é ressalvada a possibilidade de inexistir vínculo familiar entre as partes para que a violência esteja ao abrigo da Lei Maria da Penha. Este é mais um conceito vanguardista, uma vez que vínculos afetivos não são da ordem da sexualidade (...). Relações que geram posições hierárquicas de poder e opressão têm levado a doutrina (DIAS, 2019).

Por outro lado, o discurso de alguns operadores do direito parece refletir uma espécie de apropriação perversa das categorias de análise, conceitos e achados empíricos acumulados em 30 anos de pesquisas sobre as respostas judiciais aos 
problemas de violência contra as mulheres. Sem a necessária apropriação do debate teórico, tem se tornado cada vez mais frequente a afirmação de que as mulheres não querem a condenação de seus agressores, o que tem amplamente justificado o arquivamento de inquéritos e processos e a suspensão de medida de proteção. Consequentemente, ainda que às vezes pareça usar nova roupagem, o que se verifica é o exercício de uma política criminal que coloca a defesa da família à frente da defesa dos direitos individuais (PASINATO,2010).

\section{RESULTADOS E DISCUSSÃO}

Verificou-se dos relatos que muitas mulheres sequer se dão conta de que já sofreram violência obstétrica. Ademais, identificou-se que inexiste preocupação em quantificar a violência obstétrica sofrida por mulheres na esfera privada, tendo em vista que se trata de uma violência que, muitas vezes, ocorre em hospitais e em um momento de vulnerabilidade das mulheres, algo que parece não afrontar ninguém. Entretanto, muitas mulheres carregam durante toda uma vida marcas da violência, muitas inclusive não têm interesse em novamente gestar, carregando traumas psicológicos e físicos.

Vale pontuar que a violência não atinge somente a mulher, mas também o nascituro, ou muitas vezes o recém-nascido, apresentando, portanto, um efeito multiplicador, naturalizado e invisível para a sociedade. Desse modo, ao não denunciar as situações de violência obstétrica a mulher se mantém no mundo da submissão, interno e reprodutor, fruto da ideologia patriarcal e resultando na sacralização da maternidade, e à lei do silêncio.

Por outro lado, o nascimento do filho, coloca a mulher, muitas vezes, com o pensamento de ser merecedora da violência obstétrica vivenciada em razão da romantização da maternidade, passando a mulher, embora vulnerável, a ter medo, vergonha, sentimento de incapacidade, impotência, e consequentemente vivencia um estresse psicológico. 


\section{CONSIDERAÇÕES FINAIS}

Diante da roda de conversa sobre violência obstétrica foi possível perceber que esta metodologia favorece achados científicos a partir das experiências relatadas pelos participantes, possibilitando também o despertar para novos olhares e experiências, resultando na ampliação da realidade vivenciada por muitas mulheres, desenvolvendo entre os participantes a habilidade de falar e escutar, com interação e respeito mútuos.

Conclui-se, portanto que, em razão da relação de afeto que ocorre entre a paciente e médico, que independe de coabitação, entende-se perfeitamente cabível a aplicação da Lei Maria da Penha aos casos de violência obstétrica, não sendo necessária a criação de mais uma norma para regulamentar tal questão. Por outro lado, há quem defenda que não há no Brasil legislação que conceitue ou combata a violência obstétrica.

Ressalte-se, entretanto, que, sem muito esforço, a violência obstétrica é uma violação aos direitos humanos, aos direitos fundamentais, aos direitos de personalidade, tendo em vista todos os sofrimentos vivenciados pelas mulheres, nascituro, o recém-nascido e muitas vezes os familiares, podendo também encontrar amparo na legislação civilista. Acrescenta-se ainda o Código de Ética médica que também regulamenta algumas situações de violência obstétrica por analogia.

Com o presente estudo, infere-se que a promulgação de uma lei tipificando a conduta de violência obstétrica é insuficiente para rechaçar tal conduta. Logo, é necessário investir em políticas públicas sérias de enfrentamento à violência, tendo em vista a estruturação capitalista, racista e patriarcal da sociedade brasileira. O investimento em políticas públicas deve ocorrer em trabalho, educação, saúde, assistência social, previdência e habitação para mulheres em uma perspectiva feminista, a fim de promover a autonomia e emancipação das mulheres.

Por outro lado, necessário também a efetividade de uma rede de prevenção, proteção e combate à violência contra a mulher composta por Casas abrigo, Centros de Referência, Delegacias especializadas de atendimento à mulher e juizados especiais, com equipes bem treinadas e recursos suficientes, que em Santo Antônio 
de Jesus é ainda um projeto muito incipiente, trazendo para as mulheres da cidade, seja da zona urbana ou rural, um distanciamento no acesso aos equipamentos sociais e às políticas públicas.

A falta de informação, juntamente com o medo, vergonha de denunciar ou até mesmo a romantização do parto, faz com que haja o silenciamento e muitas mulheres vítimas da violência obstétrica. Desse modo, garantir a universalidade do acesso aos serviços de saúde sexual e reprodutiva, incluindo o planejamento familiar é uma medida que se impõe.

Desse modo, considera-se positiva a experiência aqui relatada, na medida em que se pode contribuir para novas discussões e estudos sobre o tema a partir do desenvolvimento de novas metodologias. Para os próximos estudos fica a possibilidade de transcrições de falas e análise de discursos dos participantes.

A análise que permitiu chegar a essas considerações baseou-se nos relatórios elaborados pelos participantes, na observação, e estudos da doutrina e legislação sobre o tema. Sugere-se que mais estudos sejam feitos no sentido de disseminar informações sobre a violência obstétrica.

\section{REFERÊNCIAS}

AMORIM, Fernanda Pacheco. Respeita as minas. Inteligência Artificial e violências contra a mulher.EMAIS Editora e Livraria Jurídica. 1aㅡ Edição. Florianópolis (SC), 2019.

ARAUJO, M. Gênero e violência contra a mulher: o perigoso jogo de poder e dominação. Psicologia para América Latina, São Paulo, n. 14, 2008.

CAVALCANTI, S.V.S.F. Violência Doméstica: análise da Lei "Maria da Penha", n 11.340/06. Editora Podivm, Salvador, p. 29, 2007.

CISNE, Mirla. Direitos humanos e violência contra as mulheres: uma luta contra a sociedade patriarcal-racista-capitalista. Serviço Social em Revista, v. 18, n. 1, p. 138-154, 2015.

DA SILVA, Michelle Gonçalves et al. Violência obstétrica na visão de enfermeiras obstetras. Revista da Rede de Enfermagem do Nordeste, v. 15, n. 4, p. 720-728, 2014. 
DEFENSORIA PÚBLICA DO ESTADO DE SÃO PAULO. Conversando sobre violência Obstétrica 2014. Disponível em: < https://docs.wixstatic.com/ugd/404636_ff691d43c5f24 20aab062d883e0a8cba.pdf > . Acesso em: 15 de dezembro de 2019.

DEFENSORIA PÚBLICA DO ESTADO DE SÃO PAULO. (2013). Violência Obstétrica: você sabe o que é? Núcleo especializado de promoção e defesa dos direitos da mulher e Associação Artemis. Escola da Defensoria Pública do Estado. São Paulo. Disponível em: . Acesso em: 17 dezmebro. 2019.

DIAS, Maria Berenice. A Lei Maria da Penha na Justiça. 5ª Edição atualizada e ampliada. Salvador. Editora Juspodiuvm. 2019.

DINIZ, N.M.F.; LOPES, R.L.M.; GESTEIRA, S.M.A.; ALVES, S.L.B.; GOMES, N.P. Violência conjugal: vivencias expressas em discursos masculinos. Revista escola de enfermagem da USP, 2003.

DINIZ, Simone; SALGADO, Heloisa; ANDREZZO, Halana; CARVALHO, Paula; CARVALHO, Priscila; AGUIAR, Cláudia; NIY, Denise. Violência obstétrica como questão para a saúde pública no Brasil: Origens, definições, tipologia, impactos sobre a saúde materna e propostas pata sua prevenção. In: Journal of Human Growth and Development, 2015. Acesso em 06/12/2019. Dísponível em: file://C:/Users/ncrds7154503/Downloads/pt-19\%20(1).pdf

DIUANA, Vilma et al. Direitos reprodutivos das mulheres no sistema penitenciário: tensões e desafios na transformação da realidade. Ciência \& Saúde Coletiva, v. 21, p. 2041-2050, 2016.

DO NASCIMENTO NETO, José Osório et al. Violência obstétrica como violência de gênero e violência institucionalizada: breves considerações a partir dos direitos humanos e do respeito às mulheres. Cadernos da Escola de Direito, v. 2, n. 25, p. 48-60, 2016.

FEDERAÇÃO BRASILEIRA DAS ASSOCIAÇÕES DE GINECOLOGIA E OBSTETRÍCIA (FEBRASGO). Posicionamento oficial do Ministério da Saúde sobre o termo "violência obstétrica. 2019. Disponível em: Acesso em: 03 de dezembro de 2019.

FUNDAÇÃO PERSEU ABRAMO. Mulheres brasileiras e gênero no espaço público e privado: pesquisa de opinião pública. 2010. Disponível em: . Acesso em: 01/12/2019.

GUERRA, G. B. (2012). Violência obstétrica. Revista de la Facultad de Medicina, 31(1), 5-6. 
IPEA. Fórum Brasileiro de Segurança Pública. Atlas da Violência 2019. Rio de Janeiro, RJ. 2019. Acesso em 28 de dezembro de 2019, disponível em:

http://www.ipea.gov.br/portal/index.php?option=com_content\&view=article\&id=34784 \&ltemid $=432$

KLEBA, M. E.; WENDAUSEN, A. Empoderamento: processo de fortalecimento dos sujeitos nos espaços de participação social e democratização política. Saúde soc., São Paulo , v. 18, n. 4, p. 733-743, 2009.

MAGALHÃES, T. A. L. O papel da mulher na sociedade. Revista da Faculdade de Direito, Universidade de São Paulo, n. 75, p. 123-134.

MATTAR, LAURA DAVIS; DINIZ, CARMEN SIMONE GRILO. Hierarquias reprodutivas: maternidade e desigualdades no exercício de direitos humanos pelas mulheres Comunicação Saúde Educação. v.16, n.40, 2012. Acesso em: 09/12/2019. Disponível em: https://www.scielosp.org/pdf/icse/2012.v16n40/107-120/pt.

Mattar LD, Diniz CSG. Hierarquias reprodutivas: maternidade e desigualdades no exercício de direitos humanos pelas mulheres. Interface (Botucatu) 2012; 16(40):107-119.

MISAKA, Marcelo Yukio. Violência doméstica e familiar contra a mulher: em busca do seu conceito. Juris Plenum. Doutrina, Jurisprudência, Legislação, n.13, p. 83-87, Caxias do Sul, jan. 2007.

MOURA, Adriana Borges Ferro; LIMA, Maria da Glória Soares Barbosa. A Reinvenção da Roda: Roda de Conversa, um instrumento metodológico possível. Interfaces da Educação, v. 5, n. 15, p. 24-35, 2015.

$\mathrm{NUCCI}$, Guilherme de Souza. Leis penais e processuais penais comentadas. 108. ed. São Paulo: Livraria RT, 2017.

ORGANIZAÇÃO MUNDIAL DE SAÚDE (2014). Declaração para prevenção e eliminação de abusos, desrespeito e maus-tratos durante o parto em instituições de saúde.2014. Disponível em: Acesso em: 20 de dezembro de 2019.

PALMA, Carolina Coelho; DONELLI, Tagma Marina Schneider. Violência obstétrica em mulheres brasileiras. Psico, v. 48, n. 3, p. 216-230, 2017.

PASINATO, Wânia. Violência contra as mulheres e legislação especial, ter ou não ter? Eis uma questão. Revista Brasileira de Ciências Criminais, n. 70, p. 321360, jan.-fev. 2008.

PASINATO, Wânia. Estudo de Caso sobre o Juizado de Violência Doméstica e Familiar contra a Mulher e a Rede de Serviços de Cuiabá - Mato Grosso. 
Relatório Final. Salvador: Observe - Observatório Lei Maria da Penha. 2009. 103 p.

Disponível em: http://www.observe.ufba.br/_ARQ/estudodecaso.pdf

PASINATO, Wânia. Lei Maria da Penha. Novas abordagens sobre velhas propostas. Onde avançamos?. Civitas-Revista de Ciências Sociais, v. 10, n. 2, p. 216-232, 2010.

PIOVESAN, Flavia. Os direitos reprodutivos como direitos humanos. Buglione S, organizadora. Reprodução e Sexualidade: Uma questão de justiça. Porto Alegre: Sergio Antonio Fabris Editor e Themis-Assessoria Jurídica e Estudos de Gênero, 2002.

PITANGUY, Jacqueline. Os direitos reprodutivos das mulheres e a epidemia do Zika vírus. Cadernos de Saúde Pública, v. 32, p. e00066016, 2016.

ROMANO, R. T. Noções gerais da família no direito romano. JusBrasil, maio 2017.

SAFFIOT, Heleieth iara Bongiovani. Gênero, patriarcado, violência. $2^{\underline{a}}$ reimpressão. Editora Fundação Perseu Abramo. São Paulo. 2004, p. 35.

SAMPAIO, Juliana et al. Limites e potencialidades das rodas de conversa no cuidado em saúde: uma experiência com jovens no sertão pernambucano. Interface-Comunicação, Saúde, Educação, v. 18, p. 1299-1311, 2014.

SERAFIM, Fabrízia Pessoa. Teoria feminista do direito aplicada: discussão sobre a prática indiscriminada da episiotomia no Brasil. Periódicos UFPB, Paraíba, 2010, v.1 n. 2; disponível em: http://periodicos.ufpb.br/ojs2/index.php/ged/article/view/9701, Acesso em 15/12/2019. P. 6-9. 